\title{
Autoantibodies in Patients with Chronic Obstructive Pulmonary Disease
}

\author{
Carol A. Feghali-Bostwick ${ }^{1 *}$, Aneal S. Gadgil1*, Leo E. Otterbein ${ }^{2}$, Joseph M. Pilewski ${ }^{1}$, Michael W. Stoner ${ }^{1}$, \\ Eva Csizmadia2, Yingze Zhang', Frank C. Sciurba1, and Steven R. Duncan' \\ ${ }^{1}$ Division of Pulmonary, Allergy, and Critical Care, University of Pittsburgh Medical Center, Pittsburgh, Pennsylvania; and ${ }^{2}$ Transplant Center, \\ Department of Surgery, Beth Israel Deaconess Medical Center, Boston, Massachusetts
}

Rationale: Adaptive immune responses are present in patients with chronic obstructive pulmonary disease (COPD), and it has been postulated that these processes could be autoreactive.

Objectives: To ascertain if humoral autoimmunity could play a role in COPD pathogenesis.

Methods: Circulating IgG autoantibodies were detected by immunofluorescence and immunoprecipitation. Immunohistochemistry and immunofluorescence were used to evaluate intrapulmonary $\operatorname{lgG}$ and complement (C3) deposition in human lung explants. Autoantibody pathogenicity was also investigated with an antibody-dependent cell-mediated cytotoxicity assay.

Measurements and Main Results: The prevalence of anti-HEp-2 epithelial cell autoantibodies in $\mathbf{4 7}$ smokers/former smokers with COPD (GOLD stages 1-4) was greater than among 8 subjects with a smoking history but normal spirometry and 21 healthy control subjects who had never smoked (68 vs. 13 vs. $10 \%$, respectively; $P<0.0001$ ). Antibodies against primary pulmonary epithelial cells were found in 12 of 12 patients with COPD versus 3 of 12 never-smoked control subjects $(P<0.001)$. Self-antigens immunoprecipitated from 34 of 35 (97\%) of COPD plasmas (vs. 0/12 never-smoked controls). Antibodies against a particular $130-\mathrm{kD}$ autoantigen $(n=7)$ were associated with decreased body mass index (23.2 \pm 2.1 vs. $29.5 \pm$ $1.0 \mathrm{~kg} / \mathrm{m}^{2}, P=0.007$ ). Intrapulmonary immune complexes were present in six of six and C3 was seen in five of six COPD lung explants, unlike zero of six and one of six normals, respectively. Cytotoxicity of pulmonary epithelial cells by allogeneic mononuclear cells also increased $46 \%$ after incubation with COPD plasmas $(n=10)$, compared with identical treatments with eight normal specimens $(P=0.03)$.

Conclusions: IgG autoantibodies with avidity for pulmonary epithelium, and the potential to mediate cytotoxicity, are prevalent in patients with COPD. Autoreactive adaptive immune responses may be important in the etiology of this disease.

Keywords: autoimmunity; humoral immunity; B cells; emphysema

Chronic obstructive pulmonary disease (COPD) is a major worldwide medical problem, resulting in millions of deaths annually, and inestimable health care expenditures and productivity losses $(1,2)$. Long-term exposure to tobacco smoke is the primary risk factor for COPD. However, smoking-associated lung injury is a complex heterogeneous syndrome with an incompletely un-

(Received in original form January 2, 2006; accepted in final form October 22, 2007) Supported in part by National Institutes of Health grants 1RO1HL073241, 1RO1AR050840, and 1P50 HL084948.

*These authors contributed equally to this article.

Correspondence and requests for reprints should be addressed to Steven R. Duncan, M.D., Pulmonary, Allergy, and Critical Care Medicine, 628 NW MUH, 3459 Fifth Avenue, University of Pittsburgh, PA 15213. E-mail: duncsr@upmc.edu This article has an online supplement, which is accessible from this issue's table of contents at www.atsjournals.org

Am J Respir Crit Care Med Vol 177. pp 156-163, 2008

Originally Published in Press as DOI: 10.1164/rccm.200701-0140C on November 1, 2007

Internet address: www.atsjournals.org

\section{AT A GLANCE COMMENTARY}

Scientific Knowledge on the Subject

The pathologic mechanisms involved in progression of chronic obstructive pulmonary disease (COPD) remain unknown, but immunologic processes have been implicated.

What This Study Adds to the Field

IgG autoantibodies with avidity for pulmonary epithelium, and the potential to mediate cytotoxicity, are prevalent in patients with COPD. Autoreactive adaptive immune responses may be important in the etiology of this disease.

derstood pathogenesis (3). Illness susceptibility appears to be highly variable, and severe disease occurs in only a minority of long-term tobacco smokers, suggesting that superimposed processes are the final determinants of COPD development $(2,4)$.

Recent evidence supports a likely role of adaptive immune responses in progression of COPD, including correlations of disease severity with characteristics of intrapulmonary and peripheral T cells (5-11). Antigen-specific "armed" effector T cells can cause various tissue injuries by direct cytopathic effects, production of diverse proinflammatory mediators, and/or recruitment and activation of other effector cells, including the provision of facultative help to antibody (and autoantibody)producing B cells $(12,13)$. In particular, antibody isotype switch (e.g., from IgM to $\mathrm{IgG}$ ), with increased antigen avidities and enhanced potential for pathogenesis, is typically dependent on activation (help) provided by CD4 T cells with unique specificity against the peptide epitopes presented by individual, antibody-producing B cells (14).

Given the presence of active adaptive $\mathrm{T}$-cell responses in COPD (5-11), we undertook a series of investigations to look for the presence of autoantibody production in these patients. The present studies show that IgG antibodies with avidity against pulmonary airway epithelial and endothelial cells, and the potential to mediate pathogenic effects, are prevalent in patients with COPD. Appreciation of these autoimmune processes may ultimately enable the development of novel diagnostic, prognostic, and/or treatment approaches for this otherwise medically refractory disease.

Some of the results of these studies have been previously reported in the form of an abstract (15).

\section{METHODS}

See the online supplement for additional methodologic details.

\section{Subjects}

Subjects with COPD with tobacco-smoking histories of 10 pack-years or more were recruited through the Emphysema-COPD Research Center 
(ECRC) at the University of Pittsburgh. All subjects were stable at the time of the examination, and had no known comorbidities. GOLD (Global Initiative for Chronic Obstructive Lung Disease) scores were assigned on the basis of pulmonary function criteria (16). Subjects with a smoking history of 10 pack-years or more (either past or current), but normal spirometry (smoking control subjects), were also recruited through the ECRC. Healthy control subjects with no history of smoking (never-smoked control subjects) were recruited by solicitation.

Blood was obtained from subjects by venipuncture and heparinized, and plasma was isolated by centrifugation.

COPD lung tissues were dissected from surgical explants from pulmonary transplantations. Normal lung specimens were similarly obtained from cadaveric harvests.

Written, informed consent was given by all subjects, in accordance with the University of Pittsburgh Institutional Review Board.

\section{Cell Lines}

Primary human pulmonary airway epithelial cells were isolated from cadaveric donor lungs and cultured as described (17). Primary human pulmonary artery endothelial cells were obtained from Cambrex (Walkersville, MD) and cultured in media (ECM) from this manufacturer. Cells for indirect immunofluroscence studies were cultured on chamber slides and fixed in $2 \%$ paraformaldehyde before staining. K562 cells for immunoprecipitations were cultured as previously described (18).

\section{Autoantibody Detection by Indirect Immunofluorescence}

Plasma samples were diluted 1:40 in phosphate-buffered saline, and incubated with either HEp-2 cells (Fluorescent HEp-2000 ANA; ImmunoConcepts, Sacramento, CA) or human pulmonary cells (see above) for 30 minutes. IgG antibodies were detected using fluorescein isothiocyanate-conjugated anti-human IgG antibody. Fluorescent microscope images were characterized by blinded investigators.

\section{Autoantibody Immunoprecipitation}

Autoantibodies were also detected in plasma by immunoprecipitation (IP), as detailed previously (18) (see also the online supplement). Standard autoantibody reference samples from patients with known connective tissue diseases were used as positive controls.

\section{Immunohistochemistry for Detection of Immune Complexes}

Explanted human lung tissues were fixed in paraformaldehyde, sectioned, and successively incubated with mouse (IgM) anti-human IgG (Serotec, Oxford, UK) followed by biotinylated goat anti-mouse IgM secondary antibody (Vector Laboratories, Burlingame, CA). AB Complex HRP (Dako Cytomation, Glostrup, Denmark) was added and color developed with DAB substrate. Microscopic images of six to nine randomly selected fields per specimen were scored by an investigator blinded to subject characteristics.

\section{Immunofluorescence for Detection of Complement (C3)}

Frozen human lung tissues were cut, paraldehyde fixed, successively incubated with chicken anti-human C3 antibody (Genesis Biotech, Inc., Boca Raton, FL) and Alexa Fluor-conjugated goat anti-chicken IgG antibody (Invitrogen, Carlsbad, CA), and then counterstained with Hoechst 33258 (Invitrogen). Microscopic images were scored as described above.

\section{Antibody-dependent Cell-mediated Cytotoxicity}

Subconfluent single-donor human pulmonary epithelial cells were pulsed with ${ }^{3} \mathrm{H}$-thymidine $(1 \mu \mathrm{Ci})$ for 24 hours and then incubated with either tissue culture media (media control) or plasma specimens, in turn from either normal subjects or patients with COPD. Single-donor allogeneic peripheral blood mononuclear cells (PBMNC) $\left(9 \times 10^{5}\right.$ cells/well) were added (19), and residual ${ }^{3} \mathrm{H}$-thymidine incorporation measured 20 hours later. Relative cytoxicity was calculated using a JAM test to detect DNA fragmentation, described elsewhere (20). Specific antibody cytotoxicity in COPD and normal plasma-pulsed wells, re- spectively, was calculated by subtracting the relative cytotoxicity of media controls.

\section{RESULTS}

\section{Subjects}

Characteristics of the 47 subjects with COPD are detailed in Table 1. Because cigarette smoking has been reported to affect immunoglobulin and autoantibody production (21), separate analyses of the subjects with COPD who no longer smoke were also subsequently denoted. There were no systematic differences of demographic or physiologic parameters between the aggregate group of subjects with COPD versus the subpopulation of those with airflow obstruction who were former smokers (cessation $>3 \mathrm{mo}$ ) (Table 1). The eight smoking control subjects (with normal spirometry) had a male predominance (nonsignificantly different, $\chi^{2}$ ) and lesser tobacco smoking exposures than the subjects with COPD, but were otherwise well matched with respect to demographic characteristics (Table 1). The ages (60 $\pm 2 \mathrm{yr}$ ) and sex distributions (48\% male) of the 21 healthy, never-smoked control subjects were similar to those of the patients with COPD. All of the subjects studied here were white except for one African American with COPD (GOLD stage 2).

\section{Presence of Antiepithelial Antibodies}

Plasma samples from all subjects were screened for the presence of antiepithelial (HEp-2) IgG antibodies by indirect immunofluorescence. The proportion of subjects with autoantibodies was markedly increased among those with COPD compared with former or current smokers with normal spirometry (smoking control subjects) and the never-smoked control subjects (68, 13 , and $10 \%$, respectively) (Figure $1 \mathrm{~A})$. There were no significant differences in antibody prevalence within the various GOLD

TABLE 1. CHARACTERISTICS OF SUBJECTS WITH CHRONIC OBSTRUCTIVE PULMONARY DISEASE

\begin{tabular}{|c|c|c|c|}
\hline & $\begin{array}{l}\text { COPD } \\
\text { (All) }\end{array}$ & $\begin{array}{c}\text { COPD } \\
\text { (Former Smokers Only) }\end{array}$ & Smoking Controls \\
\hline Number & 47 & 38 & 8 \\
\hline Age, yr & $63 \pm 1$ & $64 \pm 1$ & $63 \pm 3$ \\
\hline Sex, \% male & 53 & 47 & 75 \\
\hline \multicolumn{4}{|l|}{ GOLD stage, $n$} \\
\hline 1 & 8 & 5 & \\
\hline 2 & 14 & 10 & \\
\hline 3 & 11 & 10 & \\
\hline 4 & 14 & 13 & \\
\hline $\mathrm{FEV}_{1} \%$ predicted & $50 \pm 4$ & $47 \pm 4$ & $95 \pm 4^{*}$ \\
\hline $\mathrm{FEV}_{1} / \mathrm{FVC}$ & $0.44 \pm 0.02$ & $0.42 \pm 0.02$ & $0.78 \pm 0.2^{*}$ \\
\hline D LCO $_{\text {Cpredicted }}$ & $48 \pm 4$ & $43 \pm 4$ & $67 \pm 3^{\dagger}$ \\
\hline Smoking, pack-years & $55 \pm 4$ & $50 \pm 4$ & $28 \pm 3^{*}$ \\
\hline $\mathrm{BMI}, \mathrm{kg} / \mathrm{m}^{2}$ & $28.4 \pm 0.9$ & $29.1 \pm 1.0$ & $27.7 \pm 1.5$ \\
\hline
\end{tabular}

Definition of abbreviations: $\mathrm{BMI}=$ body mass index; $\mathrm{COPD}=$ chronic obstructive pulmonary disease; $\mathrm{L}_{\mathrm{CO}}=$ diffusing capacity for carbon monoxide, as a percentage of predicted values; GOLD = Global Initiative for Chronic Obstructive Lung Disease.

"Former Smokers Only" denotes the subpopulation from within the total COPD group who no longer smoke (cessation $>3$ mo previously). "Smoking Controls" denotes subjects with a history of tobacco smoking ( $>10$ pack-years) but normal spirometry. Two of these subjects were smoking at the time of testing, whereas the others had quit more than 3 months previously. None of these parameters were significantly different in intergroup comparisons between the two COPD groups. GOLD scores are established on the basis of pulmonary function tests (16).

${ }^{*} P<0.001$ in comparisons of all subjects with COPD versus smoking control subjects.

${ }^{\dagger} P<0.03$ in comparisons of all subjects with COPD versus smoking control subjects. 
A

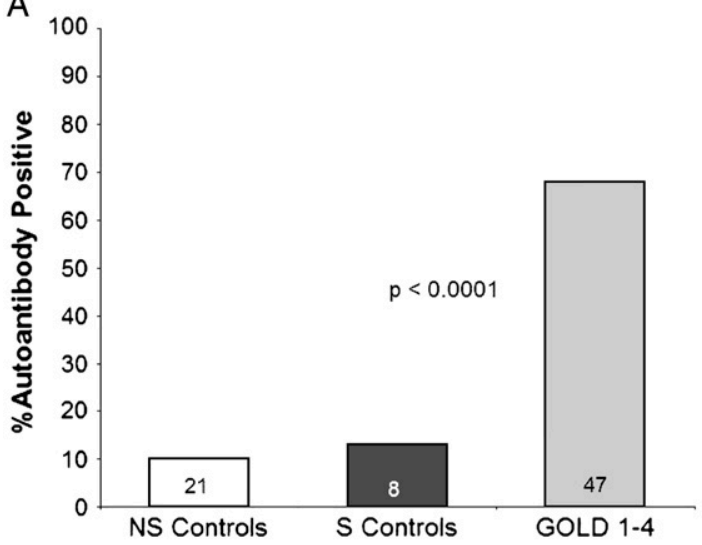

C

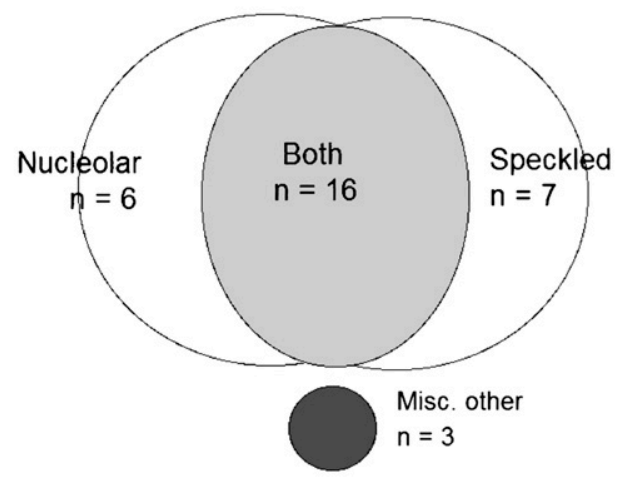

D
B
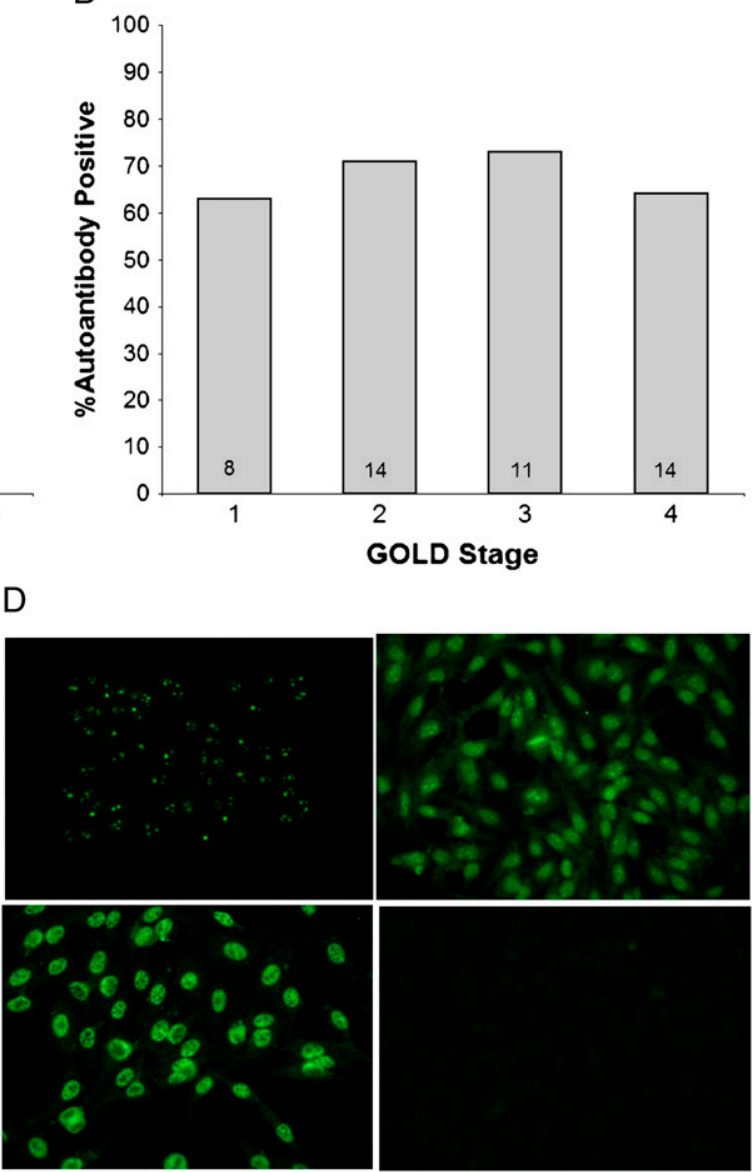

Figure 1. Antiepithelial autoantibodies in patients with chronic obstructive pulmonary disease (COPD). (A) The prevalence of autoantibodies detected by indirect immunofluorescence is much greater among subjects with COPD and abnormal expiratory airflow obstruction (GOLD stages 1-4) than in either healthy normal control subjects with no smoking history (NS Controls) or current or ex-smokers with normal spirometry (S Controls). Numbers of subjects in each population are denoted within columns. (B) Prevalences of antiepithelial autoantibodies among subjects with COPD and abnormal spirometry. Numbers of subjects in each population are denoted within columns. These respective prevalences (GOLD 1-4) are 62, 71, 73, and $64 \%$. (C) Distributions of autoantibody fluorescence patterns among those subjects with COPD who had IgG autoantibodies detected by indirect immunofluorescence. $(D)$ Predominant fluorescence patterns, clockwise from bottom left: speckled, nucleolar, mixed (both speckled and nucleolar), and negative specimens. stages 1 through 4 (Figure 1B). Two GOLD stage 4 subjects and one GOLD stage 3 subject had been maintained on stable doses of $10 \mathrm{mg}$ or less of oral prednisone at the time of testing, and both the former subjects were positive for antiepithelial antibodies, whereas the latter was negative. Similarly, the proportion of subjects with COPD who were positive for antibodies and who were taking inhaled corticosteroids $(69 \%)$ was nearly identical to that of diseased subjects not prescribed these agents (67\%) (see also Table E1 in the online supplement). Current smoking status also did not seem to overtly affect these measures, because the prevalences of antiepithelial antibodies among the COPD cohort of former smokers (Table 1) were nearly identical to the aggregate population (Figure 1) (i.e., 60, 64,70 , and $62 \%$ among GOLD stages 1 through 4 , respectively).

No correlation was evident between fluorescence intensity of the COPD specimens and GOLD stage $(\tau=-0.07, P=0.5$, data not shown) or autoantibody titers (see Figure E1). Fluorescence distribution patterns among the subjects with COPD are denoted in Figure 1C, and representative examples are illustrated in Figure 1D. A series of post hoc analyses were performed to evaluate whether specific fluorescent patterns were associated with particular disease manifestations. Given the often small numbers of subjects within some of these fluorescence classifications (Figure 1C), however, the power of these analyses is limited, and no significant associations were evident (see Table E2).

The presence of anticellular autoantibodies is a defining criterion of autoimmunity $(22,23)$. To minimize the possibility that the anti-hepatoma (HEp-2) antibodies are merely irrelevant epiphenomena of COPD, however, we also examined whether these immunoglobulins have activity against primary human pulmonary cells. Randomly selected plasma samples from 12 subjects with COPD (including 2 who did not have anti-HEp-2 antibodies), with varied disease severities (see Table E3), were tested at 1:40 dilutions for the presence of anti-IgG autoantibodies against primary human pulmonary cells by indirect immunofluorescence. All $12(100 \%)$ of these specimens had antipulmonary airway epithelial cell autoantibodies (see Figures E2A and E2B). In contrast, only 3 of 12 (25\%) randomly selected never-smoked control plasma samples had autoantibodies against human primary pulmonary airway epithelial cells $(P<$ 0.001 ) (Figures E2C and E2D). Six (50\%) of these COPD plasmas also had IgG with activity against pulmonary artery endothelial cells (Figures E3A and E3B).

\section{Autoantibody IP}

To further characterize the nature of the COPD-associated autoantibodies, and identify the sizes of the protein autoantigens, we used an IP assay to evaluate 35 remaining plasma samples with adequate volumes. Thirty-four (97\%) of these specimens immunoprecipitated autoantigens of various sizes (Figure 2A). Antigens of $62,75,115$, and $130 \mathrm{kD}$ predominated, and were detected in nine $(26 \%)$, nine (26\%), seven $(20 \%)$, and seven $(20 \%)$ of the COPD samples, respectively. 
A
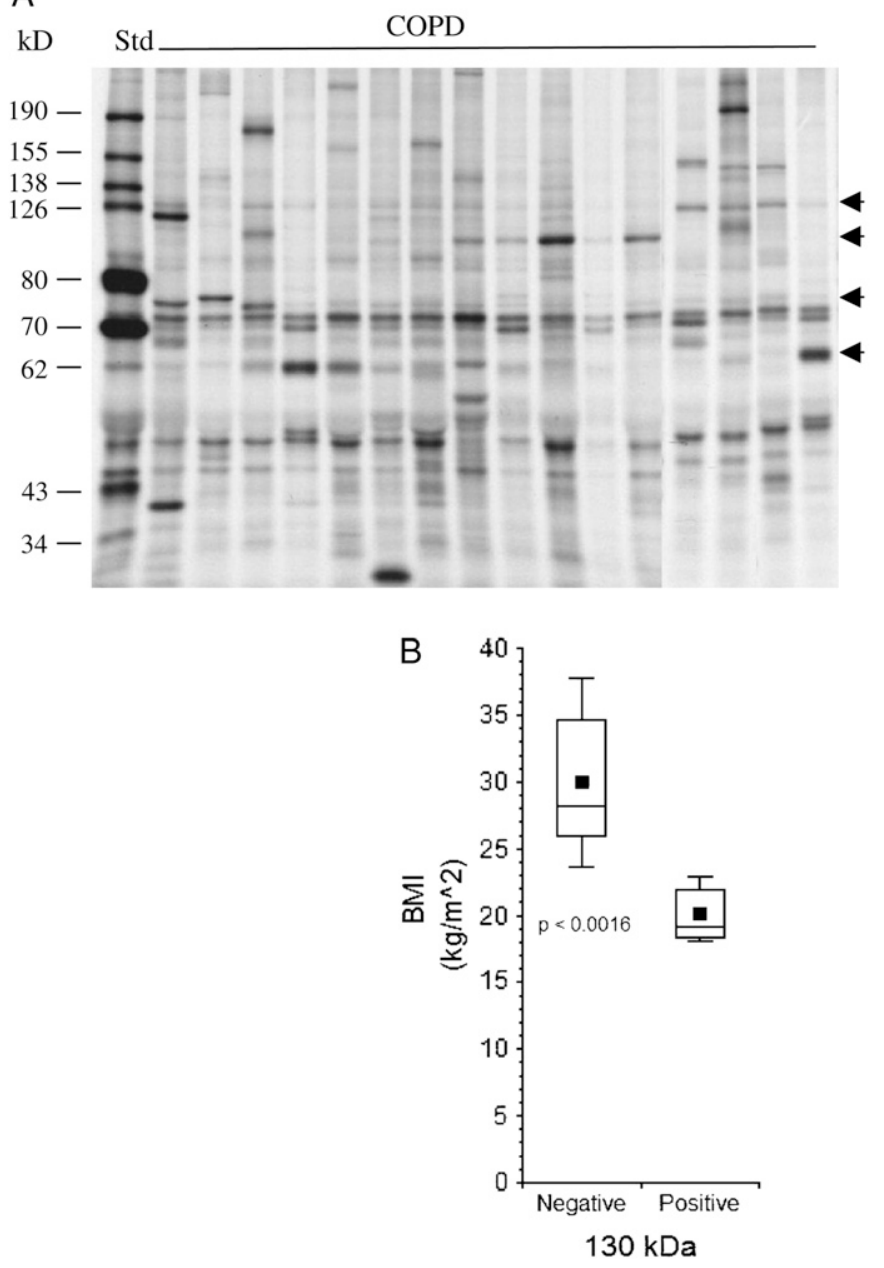

Another series of analyses was performed to evaluate the possibility that the presence of antibodies against specific cellular autoantigens (characterized by molecular weights) might be associated with selected demographic features and disease manifestations. There were no apparent associations between presence or absence of antibodies against the 62-, 75-, and 115-kD autoantigens and the demographic features and clinical parameters denoted in Table 1. However, the subjects with COPD and autoantibodies against the $130-\mathrm{kD}$ antigen had significantly decreased body mass index (BMI) compared with those patients that did not have this particular autoantibody (Figure 2B). Although the $130-\mathrm{kD}$ autoantigen-positive subjects tended to have slightly (albeit insignificantly) more airflow obstruction (see Table E4), the reduction in their BMI was disproportionately more extreme, and may be indicative of a systemic effect (e.g., weight loss and/or muscle wasting) mediated by these particular autoreactive immunoglobulins.

Several COPD samples simultaneously coprecipitated two or more of these, or other, less frequently seen, autoantigens. None of the COPD samples recognized known antigens associated with conventional connective tissue diseases (i.e., systemic lupus erythromytosis, systemic sclerosis, mixed connective tissue disease, and polymyositis), including centromere, ribonucleoprotein complexes (RNP), Scl70 (also known as topoisomerase I), RNA polymerases, Ku, polymyositis-scleroderma, Th/To, Smith (Sm), SS-A or Ro, SS-B or La, aminoacyl-tRNA synthetases, signal recognition particle (SRP), and 5' 2,2,7-trimethyl guanosine (TMG) cap (data not shown). Plasma specimens from healthy normal subjects (never-smoked control subjects) $(\mathrm{n}=12)$ were

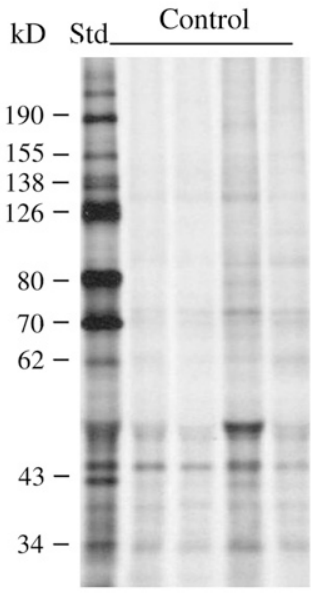

Figure 2. Detection of autoantibodies in patients with chronic obstructive pulmonary disease (COPD) by immunoprecipitation. $(A)$ Multiple bands depicting cellular antigens precipitated by autoantibodies are evident in the representative COPD specimens (composite figure). Molecular weight marker is denoted by $\mathrm{kD}$. Specimens from representative never-smoked control subjects are denoted by Control. Each lane depicts an individual subject specimen. The locations of the most prevalent autoantigens $(62,75$, $115,130)$ are denoted by arrows. (B) Body mass indexes (BMI) were significantly decreased among the seven subjects with COPD and antibodies against the 130-kD autoantigen, compared with the 28 patients lacking humoral responses to this particular antigen. negative for autoantigens (Figure 2A), as was seen in previous studies (18). One of the eight smoking control subjects (also positive for antiepithelial antibodies) had an autoantibody (or autoantibodies) against the $62-\mathrm{kD}$ antigen.

\section{IgG Deposition in Lung Tissue}

The deposition of $\mathrm{IgG}$ complexes in human lung tissues were examined using sections of pulmonary explants from six randomly selected patients with severe COPD who underwent pulmonary transplantations (see Table E5). Lung tissues from six random normal donor lungs that were not used for transplantation were used as controls. IgG deposition was detected in six of six $(100 \%)$ of the patients with COPD, within alveolar septa and small airway walls, but in none of the normal lungs (Figure 3).

\section{C3 Deposition in Lung Tissue}

Complement fixation is a potentially important mechanism of antibody-mediated cell injury. We found substantial C3 deposition in five of the six COPD lung explants described above, most typically in alveolar septa (Figure 4A). Conversely, only minimal C3 staining was apparent in one of the six normal lung specimens.

\section{Antibody-dependent Cell-mediated Cytotoxicity}

The potential for autoantibodies of patients with COPD to induce or contribute to cytolysis of lung cells was also ascertained by antibody-dependent cell-mediated cytotoxicity (ADCC) assay. Preincubating human primary pulmonary epithelial cells 

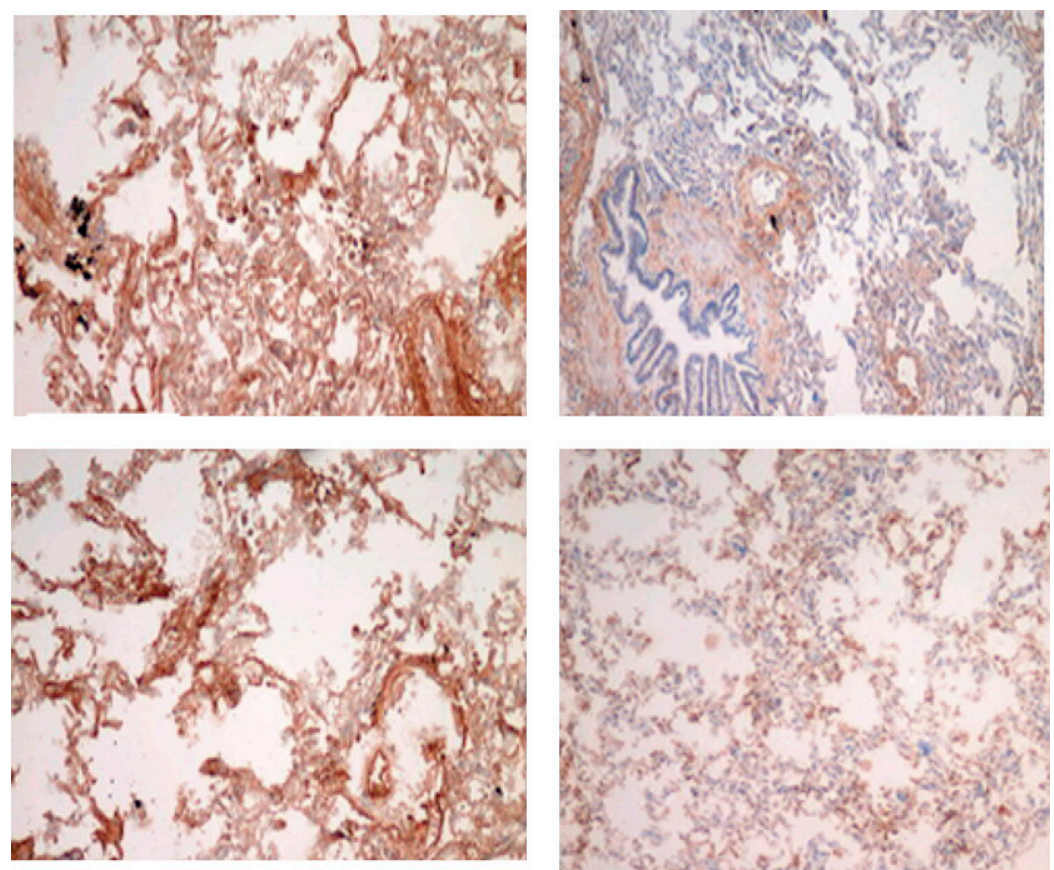

Figure 3. $\lg \mathrm{G}$ deposition in lung explants. Immunohistochemical images of explanted sections to evaluate $\lg G$ deposition (dark red-brown). Left panels: photomicrographs of representative chronic obstructive pulmonary disease (COPD) lungs showing lgG deposition within alveolar septa and small airway walls. Top right is a normal control. Bottom right is an isotype antibody control. Images are $\times 20$ original magnification. with plasma from subjects with COPD enhanced cytotoxicity of allogeneic PBMNC-epithelial cell cocultures by $46 \%$, relative to effects of the incubations with normal plasmas (Figure 4B).

\section{DISCUSSION}

These data show that circulating autoantibodies are prevalent in patients with COPD. In contrast, autoantibodies were much less frequently found among age-matched healthy control subjects in concurrent, blinded analyses, and these particular prevalences are comparable to those previously reported in normal populations (21). Moreover, while cigarette smoking per se may exert immunologic effects, including decreased immunoglobulin production and increased frequencies of autoantibodies (22), the findings here do not seem either confounded or conditional on current smoking status. These autoantibodies have avidity against cells in the diseased organ (i.e., pulmonary epithelium and/or endothelium), and properties that render them potentially pathogenic (e.g., ability to mediate ADCC). Other data presented here show immune complexes and complement deposition in situ within severely diseased lungs. Altogether, the present findings fulfill conventional criteria that define the presence of antibody responses against self-antigens as "autoimmunity" $(23,24)$.

The identity and nature of the antigen or antigens that drive production of autoantibodies in patients with COPD remain unknown. Substances in cigarette smoke can chemically modify proteins and other molecules (25), thus potentially generating neoantigens or haptens that fuel primary autoreactive immune responses. In addition, autoantibodies with primary specificity against self-epitopes can result from aberrant adaptive immune responses directed against putative antigens for which tolerance has been lost or was never acquired (e.g., anatomically sequestered determinants newly exposed to immune surveillance as a result of other injuries) (26). A recent report shows that subjects with COPD frequently have T-cell reactivity and autoantibodies against elastin (27), perhaps generated after de novo exposure of elastin fragments by proteolytic enzymes from activated neutrophils and/or macrophages. The role of these particular antibodies in the pathogenesis of COPD remains uncertain, however, and antielastin antibodies are common among normal individuals and patients afflicted with a variety of other extrapulmonary disorders (28-30).

Autoantibodies can also arise in the course of immune responses that are initially and more appropriately targeted against exogenous antigens (e.g., inhaled proteins or microbes), if molecular characteristics of the inciting antigen sufficiently "mimic" those of self-determinants (31). In addition, initially specific responses against these and other foreign antigens can generalize and spread to include targeting of quiescent selfantigens by "epitope spreading" (32). The lower airways of patients with COPD, including those with early/mild disease, or even asymptomatic smokers, are frequently colonized and/or infected with various microbes (33-36) that are capable of eliciting antibody responses (37). Thus, and in keeping with current paradigms regarding pathogenesis of other autoimmune disorders $(13,23)$, adaptive immune responses to eradicate these organisms could ultimately progress, at least in some patients, to self-reactivity via processes of microbial mimicry and/or epitope spreading $(31,32,38)$.

By whatever mechanism they arise, antibodies directed against self-antigens are often important causal factors in the pathogenesis of autoimmune diseases $(13,23,38)$. Autoantibodies can exert their pathogenic effects directly, by cross-linking cellsurface receptors or modifying cytokine productions (39), or by cell injuries mediated by antigen-antibody complexes (Figure 3), complement fixation (Figure 4A), and/or ADCC (Figure 4B) (19). The present findings that autoantibodies of subjects with COPD have avidity against human pulmonary epithelial and endothelial cells (see Figures E1 and E2) also increase the likelihood that these immunoglobulins could mediate disease pathogenesis. Moreover, the intracellular (and nucleolar) locations of the target antigens exclude the possibility that these responses are simply attributable to recently described antielastin reactions (27), because this matrix component is typically an extracellular elaboration of mesenchymal rather than epithelial (or K562) cells (40). The current findings of intrapulmonary IgG and $\mathrm{C} 3$ deposition in diseased lungs, and the overt potential of these self-reactive immunoglobulins to mediate ADCC, are highly consistent with analogous findings in conventional autoimmune 

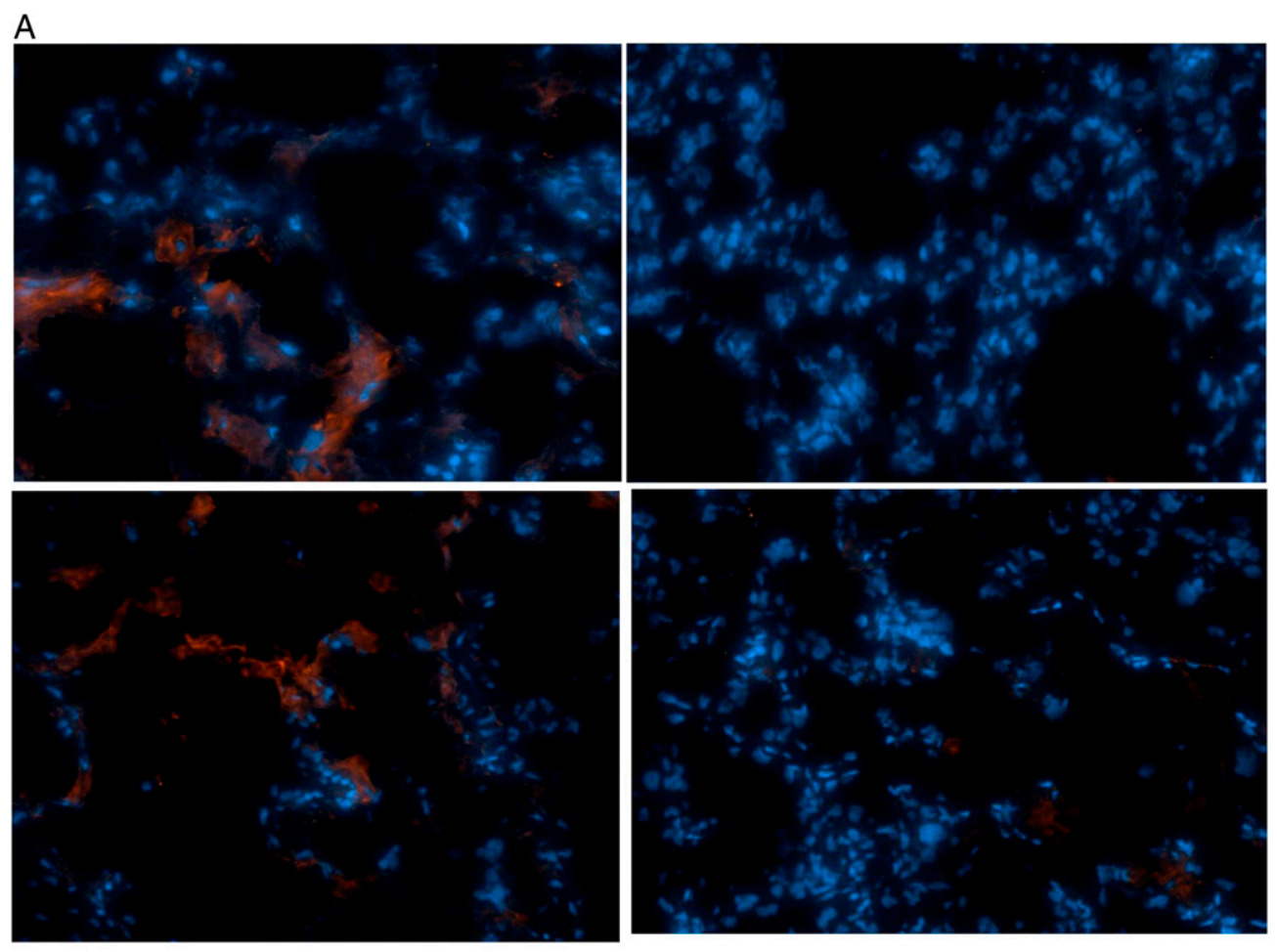

Figure 4. Complement (C3) deposition and antibody-dependent cellmediated cytotoxicity mediated by chronic obstructive pulmonary disease (COPD) autoantibodies. (A) C3 stains red against the blue cellular background in alveolar septa of two representative COPD lung sections (left panels) compared with those from normal subjects (right panels). (B) Incubation of human primary airway epithelial cells with plasmas from COPD patients $(n=10)$ enhances

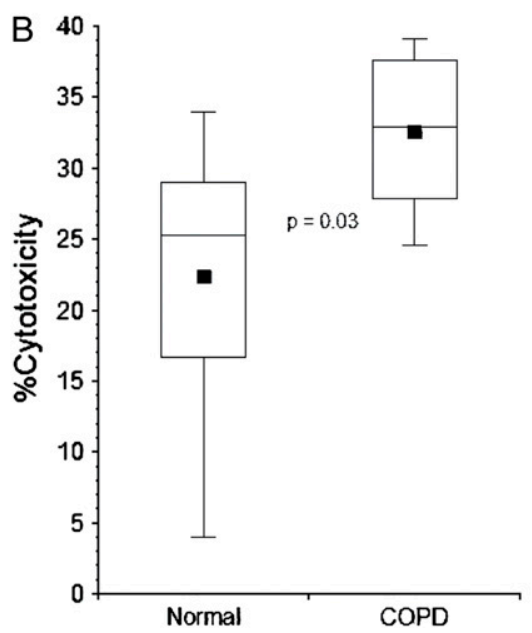
allogeneic cytotoxicity compared with effects of plasmas from normal control subjects $(n=8)$.

syndromes $(13,22)$, and implicate autoantibodies in the etiology of COPD.

The pathogenesis of most autoimmune syndromes is generally believed to be the result of complex interactions between environmental factors (e.g., cigarette smoke and/or possibly microbes) and genetic backgrounds $(13,23)$. If this autoimmune paradigm is also true in COPD, previously reported familial predilections (41) and interindividual differences in susceptibility for the disease $(2,4)$ could plausibly be explained. In addition, classical autoimmune responses tend to be self-perpetuating, and this characteristic may also account for long-term persistence of pulmonary inflammation in patients with COPD after smoking cessation (36). Moreover, autoimmune disorders frequently manifest with widespread systemic effects and involvement of multiple organ systems. Several clinical features in cohorts of patients with COPD may be a consequence of a systemic (and autoreactive) immune response (5), including increased risks of cardiovascular disease not accounted for by cigarette smoking per se (42), as well as muscle wasting (and/or decrements of BMI; see Figure 2B).
Indirect immunofluorescence assays can simultaneously detect heterogeneous autoantibodies that may have highly varied avidities, immunochemical properties, and cellular targets. Therefore, although positive test results denote the presence of an abnormality $(24,26)$, autoantibody levels (e.g., titers or intensity of fluorescent stains) are often not closely correlated with disease activity (or stage) per se (43). The association between autoantibody prevalence and disease stage in the subjects with COPD here has similarly limited precision (Figure 1B). However, identification of particular autoantibodies within a defined disease cohort can help in many cases to distinguish subgroups of afflicted patients with distinctive clinical syndromes and prognoses. For example, in systemic sclerosis, the presence of anti-Scl70 antibodies is associated with the development of pulmonary fibrosis, whereas findings of anti-RNA polymerase antibodies are more predictive of renal disease $(43,44)$. The present findings also suggest that particular autoantibodies in patients with COPD could be associated with unique clinical manifestations (Figure 2B), and the exploration of further clinical correlations with particular immunoglobulins in these patients is an area of ongoing investigation. 
The data here corroborate and extend a series of reports that implicate adaptive immune mechanisms in the pathogenesis of COPD $(5-11,27)$. The potential that these particular immune responses may have an autoimmune component has also been previously hypothesized $(5,6)$, and the development of emphysema in an animal model of T-cell-dependent autoantibody production was recently described (45). Other reports show B-cell aggregates are present in COPD lungs $(10,46,47)$ and immunoglobulin light-chain deposition in humans has previously been linked to progressive emphysema-like disease (48).

In summary, we have established that COPD is associated with autoantibodies that have avidity against pulmonary airway epithelial and, perhaps somewhat less frequently, pulmonary endothelial cells. The pathogenicity of these autoantibodies is supported by findings of in situ IgG and C3 depositions in diseased human lungs and an in vitro demonstration that these immunoglobulins can mediate ADCC. The present data are consistent with emerging paradigms that suggest that adaptive immune processes likely play a role in COPD progression $(5-11,27)$. These findings could have substantial relevance for future development of diagnostic and management modalities, and raise the potential that new approaches, possibly including directed immune modulation, could ultimately be beneficial in treatment of this disease.

Conflict of Interest Statement: C.A.F.-B. does not have a financial relationship with a commercial entity that has an interest in the subject of this manuscript. A.S.G. does not have a financial relationship with a commercial entity that has an interest in the subject of this manuscript. L.E.O. does not have a financial relationship with a commercial entity that has an interest in the subject of this manuscript. J.M.P. does not have a financial relationship with a commercial entity that has an interest in the subject of this manuscript. M.W.S. does not have a financial relationship with a commercial entity that has an interest in the subject of this manuscript. E.C. does not have a financial relationship with a commercial entity that has an interest in the subject of this manuscript. Y.Z. does not have a financial relationship with a commercial entity that has an interest in the subject of this manuscript. F.C.S. received less than $\$ 10,000$ per year for serving on advisory boards for GlaxoSmithKline and AstraZeneca, and received \$41,100 in 2005 and $\$ 21,986$ in 2006 from GlaxoSmithKline, and \$5,800 in 2005 and $\$ 15,718$ in 2006 from AstraZeneca in grants for participating in multicenter clinical trials. S.R.D. does not have a financial relationship with a commercial entity that has an interest in the subject of this manuscript.

Acknowledgment: The authors thank Stefan Ryter, Ph.D., for assistance with primary human endothelial cell culture, Joseph Latoche for isolation of primary airway epithelial cells, and Dr. Argyrios Theofilopoulos for his expert advice.

\section{References}

1. Centers for Disease Control and Prevention. Achievements in public health, 1900-1999: tobacco use-United States, 1900-1999. Morb Mortal Wkly Rep 1999;48:986-993.

2. Mannino DM. COPD: epidemiology, prevalence, morbidity and mortality, and disease heterogeneity. Chest 2002;121:121S-126S

3. Barnes PJ. Mediators of chronic obstructive pulmonary disease. Pharmacol Rev 2004:56:515-548.

4. Lange P, Parner J, Vestbo J, Schnor P, Jensen G. A 15-year follow-up study of ventilatory function in adults with asthma. $N$ Engl J Med 1998;339:1194-1200.

5. Agusti A, MacNee W, Donaldson K, Cosio M. Hypothesis: does COPD have an autoimmune component? Thorax 2003;58:832-834.

6. Voelkel N, Taraseviciene-Stewart L. Emphysema: an autoimmune disease? Proc Am Thorac Soc 2005;2:23-25.

7. Grumelli S, Corry DB, Song LZ, Song L, Green L, Huh J, Hacken J, Espada R, Bag R, Lewis DE, et al. An immune basis for lung parenchymal destruction in chronic obstructive pulmonary disease and emphysema. PLoS Med 2004;1:75-83.

8. Finkelstein R, Fraser RS, Ghezzo H, Cosio MG. Alveolar inflammation and its relation to emphysema in smokers. Am J Respir Crit Care Med 1995; 152:1666-1672.

9. Di Stefano A, Capelli A, Lusuardi M, Balbo P, Vecchio C, Maestrelli P, Mapp CE, Fabbri LM, Donner CF, Saetta M. Severity of airflow limitation is associated with severity of airway inflammation in smokers. Am J Respir Crit Care Med 1998;158:1277-1285.

10. Hogg JC, Chu F, Utokaparch S, Woods R, Elliot WM, Buzatu L, Cherniack RM, Rogers RM, Sciurba FC, Coxson HO, et al. The nature of small-airway obstruction in chronic obstructive pulmonary disease. N Engl J Med 2004;350:2645-2653.

11. Gadgil A, Zhu X, Sciurba F, Duncan S. Altered T-cell phenotypes in chronic obstructive pulmonary disease. Proc Am Thorac Soc 2006;3: $487-488$.

12. Monaco C, Andreakos E, Kiriakidis S, Feldman M, Paleolog C. T-cell mediated signaling in immune, inflammatory and angiogenic processes: the cascade of events leading to inflammatory diseases. Curr Drug Targets Inflamm Allergy 2004;3:35-42.

13. Marrack P, Kappler J, Kotzin BL. Autoimmune disease: why and where it occurs. Nat Med 2001;7:899-905.

14. Parker DC. T-cell-dependent B-cell activation. Annu Rev Immunol 1993;11:331-340.

15. Gadgil AS, Feghali-Bostwick C, Sciurba FC, Duncan SR. Presence of circulating anti-epithelial antibodies in COPD [abstract]. Proc Am Thorac Soc 2006;3:A780.

16. Celli BR, MacNee W. Standards for the diagnosis and treatment of patients with COPD: a summary of the ATS/ERS position paper. Eur Respir J 2004;23:932-946.

17. Devor DD, Pilewski JM. UTP inhibits $\mathrm{Na}+$ absorption in wild-type and DeltaF508 CFTR-expressing human bronchial epithelia. Am J Physiol Cell Physiol 1999;276:C827-C837.

18. Feghali-Bostwick C, Medsger TA, Wright TM. Analysis of systemic sclerosis in twins reveals low concordances for disease and high concordance for the presence of antinuclear antibodies. Arthritis Rheum 2003;48:1956-1963.

19. Nelson DL, Kurman CC, Serbousek DE. ${ }^{51} \mathrm{Cr}$ release assay of antibodydependent cell-mediated cytotoxicity (ADCC). In: Coligan JE, Bierer BE, Margulies DH, Shevach EM, Strober W, editors. Current protocols in immunology. Hoboken, NJ: John Wiley and Sons; 2006. pp. 7.27.1-7.27.8.

20. Livingstone A. DNA fragmentation assay (JAM test) for measuring CTL activity. In: Coligan JE, Bierer BE, Margulies DH, Shevach EM, Strober W, editors. Current Protocols in Immunology. Hoboken, NJ: John Wiley and Sons, Inc., 2006:3.11.7-3.11.1.

21. Goodwin JS, Searles RP, Tung KS. Immunologic responses of healthy elderly populations. Clin Exp Immunol 1982;48:403-441.

22. Sopori M. Effects of cigarette smoke on the immune system. Nat Rev Immunol 2002;2:372-376.

23. Ermann J, Fathman CG. Autoimmune diseases: genes, bugs, and failed regulation. Nat Immunol 2001;2:759-761.

24. Kratz A, Sluss PM, Jannuzi JL. Lewandrowski. Appendices: laboratory values of clinical importance. Table A-2. Immunology. In: Harrison's Principles of Internal Medicine. Kasper DL, Fauci AS, Longo DL, Braunwald E, Hauser SL, Jameson JL, eds. McGraw-Hill, New York, $16^{\text {th }}$ edition, 2005, Table A-3, page 2613 .

25. Cerami C, Founds H, Nicholl I, Mitsuhashi T, Giordano D, Vanpatten S, Lee A, Al-Abed Y, Vlassara H, Bucala R, et al. Tobacco smoke is a source of toxic reactive glycation products. Proc Natl Acad Sci USA 1997;94:13915-13920.

26. Guerassimov A, Zhang Y, Banerjee S, Cartman A, Webber C, Esdaile J, Fitzcharies MA, Poole AR. Autoimmunity to cartilage link proteins in patients with rheumatoid arthritis and ankylosing spondilitis. J Rheumatol 1998;25:1480-1484.

27. Lee S-H, Goswami S, Grudo A, Song L-Z, Bandi V, Goodnight-White S, Green L, Hacken-Bitar J, Huh J, Bakaeen F, et al. Antielastin autoimmunity in tobacco smoking-induced emphysema. Nat Med 2007;13: $567-569$.

28. Nicoloff G, Weiss AS, Iotova V, Tzaneva V, Petrova C, Domuschieva N, Nikolov A, Tzvetanov P, Christova P. Abnormal levels of serum antielastin antibodies in children with diabetes mellitus type 1. J Investig Med 2006;54:461-467.

29. Konova E, Atanasova M, Stoykov S, Velkova A, Shoenfeld Y. Idiotypic and anti-idiotypic elastin autoantibodies: implications for IVIg and pregnancy loss. J Autoimmun 2007;28:46-54.

30. Daskalova M, Taskov H, Dimitrova E, Baydanoff S. Humoral and cellular immune response to elastin in patients with systemic sclerosis. Autoimmunity 1997;25:233-241.

31. Oldstone MB. Molecular mimicry, microbial infection and autoimmune disease: evolution of the concept. Curr Top Microbiol Immunol 2005; 296:1-17.

32. Vanderlugt CL, Miller SD. Epitope spreading in immune mediated diseases: implications for immunotherapy. Nat Rev Immunol 2002;2:85-94.

33. Qvarfordt L, Riise GC, Andersson BA, Larsson S. Lower airway bacterial colonization in asymptomatic smokers and smokers with chronic bronchitis and recurrent exacerbations. Respir Med 2000;94:881-887. 
34. Sethi S, Maloney J, Grove L, Wrona C, Berenson CS. Airway inflammation and bronchial bacterial colonization in chronic obstructive pulmonary disease. Am J Respir Crit Care Med 2006;173:991-998.

35. Soler N, Ewig S, Torres A, Filella X, Gonzalez J, Zaubet A. Airway inflammation and bronchial microbial patterns in patients with stable chronic obstructive pulmonary disease. Eur Respir J 1999;14:1015-1022.

36. Retamales I, Elliott WM, Meshi B, Coxson HO, Pare PD, Sciurba FC, Rogers RM, Hayashi S, Hogg JC. Amplification of inflammation in emphysema and its association with latent adenoviral infection. Am J Respir Crit Care Med 2001;164:469-473.

37. Adlowitz DG, Kirkham C, Sethi S, Murphy TF. Human serum and mucosal antibody responses to outer membrane protein G1b of Moraxella catarrhalis in chronic obstructive pulmonary disease. FEMS Immunol Med Microbiol 2006;46:139-146.

38. Croxford JL, Olson JK, Miller SD. Epitope spreading and molecular mimicry as triggers of autoimmunity in the Theiler's virus-induced demyelinating disease model of multiple sclerosis. Autoimmun Rev 2002;1:251-260.

39. Wallace WAH, Howie SM. Upregulation of tenascin and TGF- $\beta$ production in a type II alveolar epithelial cell line by antibody against a pulmonary auto-antigen. $J$ Pathol 2001;195:251-256.

40. Shifen A, Mecham RP. The stumbling block in lung repair of emphysema: elastic fiber assembly. Proc Am Thorac Soc 2006;3:428-433.

41. Silverman EK. Progress in chronic obstructive pulmonary disease genetics. Proc Am Thorac Soc 2006;3:405-408.
42. Gan WQ, Man SF, Senthilselvan A, Sin DD. Association between chronic obstructive pulmonary disease and systemic inflammation: a systematic review and a meta-analysis. Thorax 2004;59:574-580.

43. Steen VD, Powell DL, Medsger TA. Clinical correlations and prognosis based on serum autoantibodies in patients with systemic sclerosis. Arthritis Rheum 1988;31:196-203.

44. Reimer G, Steen VD, Penning CA, Medsger TA, Tan EM. Correlates between autoantibodies to nucleolar antigens and clinical features in patients with systemic sclerosis (scleroderma). Arthritis Rheum 1988; 31:525-532.

45. Taraseviciene-Stewart L, Scerbavicius R, Choe KH, Moore M, Sullivan A, Nicholls MR, Fontenot AP, Tuder RM, Voelkel NF. An animal model of autoimmune emphysema. Am J Respir Crit Care Med 2005; 171:734-742.

46. Bosken $\mathrm{CH}$, Hards J, Gatter K, Hogg JC. Characterization of the inflammatory reaction in the peripheral airways of cigarette smokers using immunocytochemistry. Am Rev Respir Dis 1992;145:911-917.

47. van der Strate BWA, Postma DS, Brandsma C-A, Melgert BN, Luinge MA, Geerlings M, Hylkema MN, van den Berg A, Timens W, Kerstjens HAM. Cigarette smoke-induced emphysema: a role for the B cell? Am J Respir Crit Care Med 2006;173:751-758.

48. Colombat M, Stern M, Groussard O, Droz D, Brauner M, Valeyre D, Mal H, Taille C, Monnet I, Fournier M, et al. Pulmonary cystic disorder related to light chain deposition disease. Am J Respir Crit Care Med 2006;173:777-780. 